\title{
Heart rate and blood pressure variability as markers of sensory blockade with labour epidural analgesia
}

\author{
[La variabilité de la fréquence cardiaque et de la tension artérielle comme indi- \\ cateurs du bloc sensitif lors de l'analgésie péridurale pour le travail obstétrical]
}

Alain Deschamps MD PhD FRCPC, ${ }^{*}$ Ian Kaufman MD FRCPC, $†$ Alana Geist BSc, $\ddagger$

Steven S.B. Backman MD PhD FRCPC, $†$ Karen Loo MD FRCPC†

Purpose: To evaluate the correlation between the progression of somatosensory blockade and changes in autonomic outflow following the onset of labour epidural analgesia.

Methods: Twelve labouring parturients consented to participate in the study. Baseline electrocardiogram, blood pressure (BP) and respiratory rate were recorded for ten minutes. The epidural consisted of $0.125 \%$ bupivacaine with $50 \mu \mathrm{g}$ of fentanyl (total volume $20 \mathrm{~mL}$ ). Measurements were repeated for ten minutes after initiation of the block. The level of sensory block was measured bilaterally with loss of sensation to ice at twominute intervals. Wavelet transform was used to obtain heart rate $(\mathrm{HR})$ and $\mathrm{BP}$ variability every two minutes following the loading dose of epidural medication. High frequency power of $\mathrm{HR}$ variability was used to assess changes in parasympathetic activity. The total power of BP variability was used to assess changes in sympathetic activity. A nonparametric repeated measures ANOVA was used for the variability data, and a Spearman rank correlation test was used to evaluate the relationship between the sensory block and HR and BP variability.

Results: The sensory block progressed to T9 at ten minutes post-epidural and was the mirror image of the decrease in total power of BP variability. High frequency power of $H R$ variability increased to a plateau at six minutes post-epidural. A significant correlation was found between the increase in sensory block and the observed decrease in BP variability $(r=-1.000, P=$ 0.0028).

Conclusion: In this study of labouring parturients, BP variability correlated with the progression of both sympathetic and somatosensory block following epidural anesthesia, while HR variability was shown to be a surrogate marker of increased parasympathetic activity.
CAN J ANESTH $2007 / 54: 3 /$ pp 183-189

Objectif: Évaluer la corrélation entre la progression du bloc somato-sensitif et les changements du débit autonome après le début de l'analgésie péridurale pour le travail obstétrical.

Méthode : Douze parturientes en travail ont accepté de participer à cette étude. Les données de base d'électrocardiogramme, de tension artérielle (TA) et de fréquence respiratoire ont été enregistrées durant dix minutes. La péridurale était constituée de 0, 125 $\%$ de bupivacaïne avec $50 \mu \mathrm{g}$ de fentanyl (volume total $20 \mathrm{~mL}$ ). Les mesures ont été reprises pendant dix minutes après le début du bloc. Le niveau du bloc sensitif a été mesuré bilatéralement par la perte de sensation au froid (glace) à des intervalles de deux minutes. La transformée par ondelettes a été utilisée pour obtenir la variabilité de la fréquence cardiaque (FC) et de la TA toutes les deux minutes après l'administration de la dose de péridurale. La puissance à haute fréquence de la variabilité de la TA a été utilisée pour évaluer les changements de l'activité parasympathique. La puissance totale de la variabilité de la TA a servi à évaluer les changements de l'activité sympathique. Une ANOVA pour mesures répétées non paramétriques a été utilisée pour les données de variabilité, et un test de corrélation de rang de Spearman a servi à l'évaluation de la relation entre le bloc sensitif et la variabilité de FC et de TA.

Résultats: Dix minutes après la péridurale, le bloc sensitif a progressé jusqu'à T9 et a reflété la diminution de la puissance totale de variabilité de TA. La puissance de la haute fréquence de la variabilité de $F C$ a augmenté jusqu'à un plateau six minutes après la péridurale. Une corrélation importante a été notée entre

From the Department of Anesthesiology, ${ }^{*}$ Montreal Heart Institute, Centre universitaire de santé de l'université de Montréal, Montréal, Québec; the Department of Anesthesiology, † Royal Victoria Hospital, McGill University Health Centre, Montréal, Québec; the Research Institute of the McGill University Health Centre, Montréal, Québec; and the University of Calgary, Calgary, Alberta, Canada. Address correspondence to: Dr. Alain Deschamps, Department of Anesthesiology, Montreal Heart Institute, 5000 Bélanger Street, Montreal, Quebec HIT 1C8, Canada. Phone: 514-376-3330, ext: 3732; Fax: 514-376-8784; E-mail: a.deschamps@umontreal.ca Supported by grants from the Fédération de la Recherche en Santé du Québec, the 2003 Baxter Corporation Canadian Research Award in Anesthesia from the Canadian Anesthesiologists' Society, Association des Anesthésiologistes du Québec, and the Research Institute of the McGill University Health Centre.

Accepted for publication September 28, 2006.

Revision accepted November 29, 2006. 
l'augmentation du bloc sensitif et la diminution observée de variabilité de TA ( $r=-1,000, P=0,0028)$.

Conclusion: Dans cette étude portant sur des parturientes en travail, la variabilité de la TA fut associée à la progression des blocs sympathique et somato-sensitif suite à l'anesthésie péridurale, et il $a$ été démontré que la variabilité de la FC est un indicateur indirect d'une activité parasympathique accrue.

$\mathrm{F}$ OR the first stage of labour, epidural analgesia should ideally result in a somatosensory block sufficient to inhibit the C-fibres entering the dorsal horn of the spinal cord at the levels T10, Tl1, Tl2 and $\mathrm{Ll} .{ }^{1}$ The changes in autonomic outflow that accompany epidural block have been described recently by our group using an analysis of heart rate (HR) and blood pressure (BP) variability. ${ }^{2}$ The technique was shown to be sufficiently sensitive to measure changes in parasympathetic and sympathetic outflow, even when absolute values for HR and BP are not significantly altered. Since labouring patients are readily accessible to measure the height of somatosensory block in response to epidural analgesia, we considered that it would be relevant to correlate the changes in HR and BP variability with the progression of epidural block in this patient population. We reasoned that if a significant correlation is identified, the technique of measuring $\mathrm{HR}$ and $\mathrm{BP}$ variability would have potential clinical application in settings where it is sometimes impractical or difficult to continuously evaluate the degree of sensory block, as with regional anesthesia in the operating room. Furthermore, hemodynamic parameters tend to be stable with epidural analgesia for labour, which makes studying the relationship more practical in this patient population compared with spinal anesthesia for surgery, where hemodynamic alterations are relatively frequent. Identifying a correlation of $\mathrm{HR}$ and $\mathrm{BP}$ variability with autonomic function could eventually serve the dual purpose of indicating an adequate somatosensory level, as well as serving as a marker of impending hemodynamic instability. Therefore, in a group of labouring parturients, we tested the hypothesis that markers of autonomic outflow as assessed by HR and $\mathrm{BP}$ variability correlate closely with the progression of somatosensory block following the onset of epidural analgesia for labour.

\section{Materials and methods}

\section{Subjects}

Following approval of the study protocol from the Royal Victoria Hospital Research Ethics Board and after obtaining informed consent, 12 parturients were enrolled between August 2004 and December 2004. Multiparous or primiparous parturients in established labour presenting with uncomplicated pregnancies at term (38-40 weeks gestation) were considered for enrolment. Patients with absolute or relative contraindications to epidural analgesia or with major cardiovascular, pulmonary, neurological, endocrine, or metabolic disorders, or with a history of recent exposure to medications affecting HR (e.g., beta-adrenergic blockers or agonists, muscarinic agonists or antagonists) were excluded from the study. Patients with a cardiac rhythm other than sinus or showing multiple premature ventricular beats were also excluded.

\section{PROTOCOL}

Lead II of the electrocardiogram, respiratory rate, fetal HR (external monitor), and uterine contractions were recorded. Blood pressure was monitored continuously using a noninvasive measurement device (Colin 7000, San Antonio, TX, USA) based on tonometry of the right radial artery to obtain an arterial BP waveform. This device provides accurate assessment of systolic BP over a range of $60-250 \mathrm{mmHg}$ systolic and of diastolic BP over a range of $40-220 \mathrm{mmHg}$ with pulse rates between 30 and 180 beats. $\mathrm{min}^{-1}$. The electrocardiogram, BP, and respiratory signals were collected via an analogue-to-digital converter at a sampling rate of $1,000 \mathrm{~Hz} / \mathrm{channel}$ and were stored on a portable computer.

Control data was recorded for ten minutes with the patient in left lateral position. When the patient was in active labour and requested analgesia, a continuous epidural was established at the lumbar 3-4 interspace using standard sterile procedures and an air loss of resistance technique with a 16G Tuohy needle, without receiving a fluid bolus beforehand. A test dose of $0.125 \%$ bupivacaine $2 \mathrm{~mL}$ was used to confirm the correct position of the catheter. A total of $20 \mathrm{~mL}$ of $0.125 \%$ bupivacaine was given in incremental doses followed by $50 \mu \mathrm{g}$ of fentanyl. The patient was then placed in left lateral position, and data (see below) were recorded for ten minutes. The level of sensory block was evaluated bilaterally with ice at two-minute intervals. The patients did not receive a fluid bolus before the epidural.

Analysis of HR and BP variability was evaluated by Wavelet transform ${ }^{3}$ and calculated every two minutes for ten minutes following establishment of the epidural block. Wavelet transform allows for the analysis of rapidly changing HR and BP. Changes in high frequency (HF) power of HR variability have been shown to indicate changes in parasympathetic activity, ${ }^{2-8}$ while 
changes in all frequencies of BP variability have been correlated with changes in sympathetic activity. ${ }^{2,4,7,8}$

\section{Analysis of $H R$ and $B P$ variability}

The analysis of HR and BP variability has been previously described in detail., ${ }^{2,3}$ Briefly, the analysis extracts characteristic frequencies of a signal that is composed of the consecutive $\mathrm{R}-\mathrm{R}$ intervals for $\mathrm{HR}$ variability analysis or consecutive beat-to-beat BP for BP variability analysis. Discrete wavelet transform is used for the analysis of non-stationary signals and thus, unlike Fast Fourier transformation, there is no prerequisite for the stability of the frequency content of the signal. The analysis consists of sliding a window of different weights containing a wavelet function along the signal. The mother wavelet function used in this study is called "Daubechies 4". ${ }^{2,5}$ It was chosen as the best approximation of the shape of the signal to be analyzed. Serial lists of coefficients called "wavelet coefficients" are obtained representing the evolution of the correlation between the signal and the wavelet for different wavelet functions. The smallest scaled wavelet coefficient compares the length of two $\left(2^{1}\right)$ consecutive measurements, which is the highest frequency analyzed. The wavelet function immediately above compares the length of four $\left(2^{2}\right)$ consecutive measurements, and thus compares half as much length of the signal, and the frequency analyzed is halved compared to the previous wavelet function. In this study, the maximum number of increments forming wavelet coefficient was $5\left(2^{5}\right)$ or 32 consecutive measurements. The vari- ability power is calculated as the sum of the squares of the coefficients for each wavelet function for a given time interval. We chose two-minute intervals for HR and $\mathrm{BP}$ variability analysis. The baseline was estimated using the average of five two-minute intervals for HR and $\mathrm{BP}$ variability analysis. Power coefficients calculations were averaged over two-minute intervals, from baseline to ten minutes post-epidural. Beat-to-beat mean BP was used for the variability analysis. The total power of the BP variability signal was used as an index of sympathetic activity and was shown to decrease with epidural analgesia in our previous study. ${ }^{2}$ For HR variability, HF power (sum of levels 2, 4, and 8 ) was used for analysis of parasympathetic activity and was shown to increase with epidural analgesia in our previous study. ${ }^{2}$ The ratio of low frequency (LF) power (sum of levels 16 and 32) over HF power was also compared as a possible index of sympathetic activity. As in our previous study, ${ }^{2}$ the wavelet analysis was performed using the analytical software MATLAB ${ }^{\circledR}$ (The MathWorks, Inc., Natick ME, USA) and the dedicated Wavelet Toolbox software.

\section{STATISTICAL ANALYSIS}

The sample size calculation was estimated using previous data ${ }^{2}$ for BP variability. For a $95 \%$ power to detect a difference between means of total frequency power of $604 \mathrm{mmHg}^{2}$ with a significance of 0.05 (twosided), assuming a SD of $500 \mathrm{mmHg}^{2}$, the sample size had to be ten patients. Because non-parametric tests were used, $15 \%$ more patients were added for

TABLE Blood pressure and heart rate variability

\begin{tabular}{|c|c|c|c|c|c|c|}
\hline Time post-epidural & Baseline & $2 \mathrm{~min}$ & $4 \mathrm{~min}$ & $6 \mathrm{~min}$ & $8 \mathrm{~min}$ & $10 \mathrm{~min}$ \\
\hline $\begin{array}{l}\text { MAP } \\
(\mathrm{mmHg})\end{array}$ & $\begin{array}{l}83.9 \\
(6.4)\end{array}$ & $\begin{array}{l}84.8 \\
(11.7)\end{array}$ & $\begin{array}{l}83.5 \\
(13.2)\end{array}$ & $\begin{array}{l}78.1 \\
(8.6)\end{array}$ & $\begin{array}{l}86.5 \\
(10.7)\end{array}$ & $\begin{array}{l}79.0 \\
(11.0)\end{array}$ \\
\hline $\begin{array}{l}\text { HR } \\
\text { (beats } \cdot \min ^{-1} \text { ) }\end{array}$ & $\begin{array}{l}85.6 \\
(10.5)\end{array}$ & $\begin{array}{l}90.4 \\
(12.1)\end{array}$ & $\begin{array}{l}92.6 \\
(11.6)\end{array}$ & $\begin{array}{l}88.5 \\
(9.7)\end{array}$ & $\begin{array}{l}83.3 \\
(13.2)\end{array}$ & $\begin{array}{l}86.7 \\
(11.9)\end{array}$ \\
\hline $\begin{array}{l}\text { RR } \\
\text { (breaths } \cdot \min ^{-1} \text { ) }\end{array}$ & $\begin{array}{l}19.5 \\
(2.7)\end{array}$ & $\begin{array}{l}19.4 \\
(3.2)\end{array}$ & $\begin{array}{l}18.9 \\
(3.6)\end{array}$ & $\begin{array}{l}19.2 \\
(3.1)\end{array}$ & $\begin{array}{l}19.4 \\
(2.5)\end{array}$ & $\begin{array}{l}19.1 \\
(2.8)\end{array}$ \\
\hline $\begin{array}{l}\text { Somatosensory } \\
\text { blockade level }\end{array}$ & 0 & $\begin{array}{l}\mathrm{T} 12 \\
{[\mathrm{~T} 12]}\end{array}$ & $\begin{array}{l}\mathrm{T} 11 \\
{[\mathrm{~T} 12]}\end{array}$ & $\begin{array}{l}\mathrm{T} 10 \\
{[\mathrm{~T} 11]}\end{array}$ & $\begin{array}{l}\text { T9 } \\
{[\mathrm{T} 10]}\end{array}$ & $\begin{array}{l}\text { T8 } \\
{[\mathrm{T} 9]}\end{array}$ \\
\hline $\begin{array}{l}\text { TP of BP variability } \\
\left(\mathrm{mmHg}^{2}\right)\end{array}$ & $\begin{array}{l}5226.6 \\
(979.9)\end{array}$ & $\begin{array}{l}2748.8^{*} \\
(102.3)\end{array}$ & $\begin{array}{l}1407.3^{*} \\
(245.1)\end{array}$ & $\begin{array}{l}1282.2^{*} \\
(86.0)\end{array}$ & $\begin{array}{l}1143.3^{*} \\
(85.0)\end{array}$ & $\begin{array}{l}696.4^{*} \\
(34.7)\end{array}$ \\
\hline $\begin{array}{l}\text { HFP of HR variability } \\
\left(\mathrm{msec}^{2}\right)\end{array}$ & $\begin{array}{l}33589.9 \\
(3828.3)\end{array}$ & $\begin{array}{l}42359.0 \\
(8917.6)\end{array}$ & $\begin{array}{l}77138.0 \dagger \\
(17745.3)\end{array}$ & $\begin{array}{l}69173.1 \dagger \\
(9910.5)\end{array}$ & $\begin{array}{l}71495.7 \dagger \\
(13340.8)\end{array}$ & $\begin{array}{l}73568.6 \dagger \\
(12692.7)\end{array}$ \\
\hline
\end{tabular}

Mean values \pm SD for blood pressure (BP), heart rate (HR), respiratory rate (RR), somatosensory block level, total power (TP) of BP variability and high frequency power (HFP) of HR variability at baseline and every two minutes for ten minutes post-epidural for labour. MAP = mean arterial pressure. Numbers in parentheses are standard deviations. Numbers in brackets represent the mode of the sample data. ${ }^{*} P<0.0001$ from baseline value. $\dagger P=0.0013$ from baseline value. 
a requirement of 12 patients. Statistical analysis was performed using the software InStat ${ }^{\circledR}$ (Prism, San Diego, CA, USA) for each wavelet function at baseline and at two-minute intervals following the epidural. Data analysis was performed using the Friedman test, a nonparametric test for repeated measures ANOVA for changes over the time periods studied. Dunn's multiple comparison test was used if the ANOVA was significant. A Spearman rank correlation test was applied for non-parametric correlation to evaluate the rate of change of total power of BP variability and $\mathrm{HF}$ power of $\mathrm{HR}$ variability with the rate of change in block level. Data are presented as mean \pm SD unless otherwise specified and statistical significance was assumed with a $P<0.05$.

\section{Results}

Fifteen patients were screened for the study, three refused to participate while 12 enrolled and completed the study. The patient population was uniformly distributed with ages ranging from 26 and $34 \mathrm{yr}$, median of $31 \mathrm{yr}$, and weights ranging from 68 to 84 $\mathrm{kg}$, median of $77 \mathrm{~kg}$. Nine patients were primiparous and three were multiparous. There was no occurrence of fetal bradycardia (decrease of fetal HR of $20 \%$ from baseline). All blocks provided satisfactory labour analgesia, visual analogue scores $<2$.

Mean arterial pressure, HR and respiratory rate did not vary significantly from their respective baseline values following establishment of epidural analgesia (Table). After the second minute, patients experienced loss of sensation to ice at the dermatome level of T12 \pm 0.6 . After ten minutes, the sensory block reached an average dermatome level of T8 \pm 2.3 (Table, Figure A). The total power of BP variability (sympathetic activity) decreased steadily over time following onset of epidural block (Table, Figure B, $P<0.01$ ). The $\mathrm{HF}$ power of $\mathrm{HR}$ variability analysis (parasympathetic activity) increased significantly to a plateau $(P<0.01)$ at the fourth minute until the tenth minute post-epidural blockade (Table, Figure C). The ratio of LF over $\mathrm{HF}$ power of $\mathrm{HR}$ variability showed no correlation with somatosensory block progression (Figure D).

The Spearman rank correlation test showed a significant correlation between the decrease in BP variability and the increase in sensory block $(r=-1.000, P$ $=0.0028$ ), while the correlation between the increase in HR variability and the increase in sensory block was not significant $(\mathrm{r}=0.6571, P=0.1750)$.

\section{Discussion}

This study shows that in labouring parturients, BP variability correlates with the progression of both sympathetic and somatosensory block following epidural anesthesia, while HR variability is a surrogate marker of increased parasympathetic activity. There are several observations from these findings that have important clinical implications. First, a correlation between changes in BP variability and the progression of somatosensory block after onset of epidural blockade can be observed in the absence of changes in the absolute values of BP and HR. Changes in autonomic tone without changes in vital signs have been observed previously, ${ }^{2}$ and we obtained further confirmation that these variables are sufficiently sensitive to detect small changes in autonomic tone during the onset of epidural analgesia. Second, analysis of BP variability appears to provide a better surrogate marker of the progression of the epidural block with a gradual decrease in power coinciding with the increase in somatosensory block. This may reflect observations from previous studies that show a correlation between BP variability and changes in sympathetic tone $2,4,7,9,10$ and would closely follow the functional sympathectomy in our patients. Neuraxial blockade has been associated with an enhanced sensitivity of the autonomic response when compared to the somatosensory response. ${ }^{11}$ Furthermore, we may assume that some of the decrease in sympathetic outflow in our study was due to a decrease in pain as well as regional sympathectomy, since pain is a significant contributor to sympathetic tone.

It should not be assumed that HR variability could not be a useful marker of somatosensory blockade. The Table clearly shows that a level of Tll is reached in most patients at six minutes post-epidural blockade, and this also corresponds with a significant increase in $\mathrm{HF}$ power of $\mathrm{HR}$ variability. This increase, which has been repeatedly associated with parasympathetic outflow, 2,3,5,6,12-14 maintains a plateau thereafter. This could be sufficient to confirm adequate somatosensory block level in these patients. A reflex increase in parasympathetic outflow would be predicted from the relief of labour pain and the corresponding decrease in sympathetic tone.

Several studies have used analysis of HR variability to predict hypotension after spinal anesthesia, ${ }^{15-17}$ to prevent hypotension prior to spinal anesthesia, ${ }^{18}$ to predict morbidity and mortality from arrhythmias, ${ }^{19,20}$ as a predictor of mortality in head trauma patients, ${ }^{21,22}$ and as an index of survival in the critically ill patients. ${ }^{22-24}$ The results presented here provide another example of how analyses of $\mathrm{HR}$ and BP variability could eventually be used to assess the degree of somatosensory blockade while monitoring autonomic changes that might compromise hemodynamic stabil- 
A

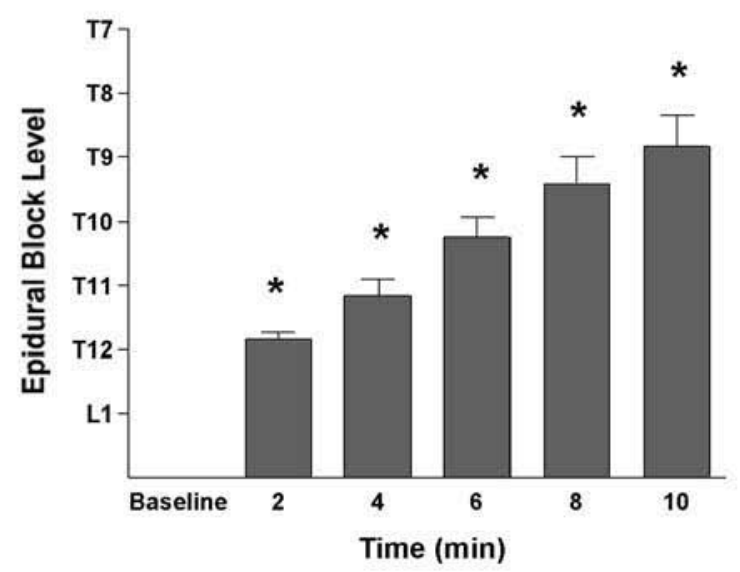

C

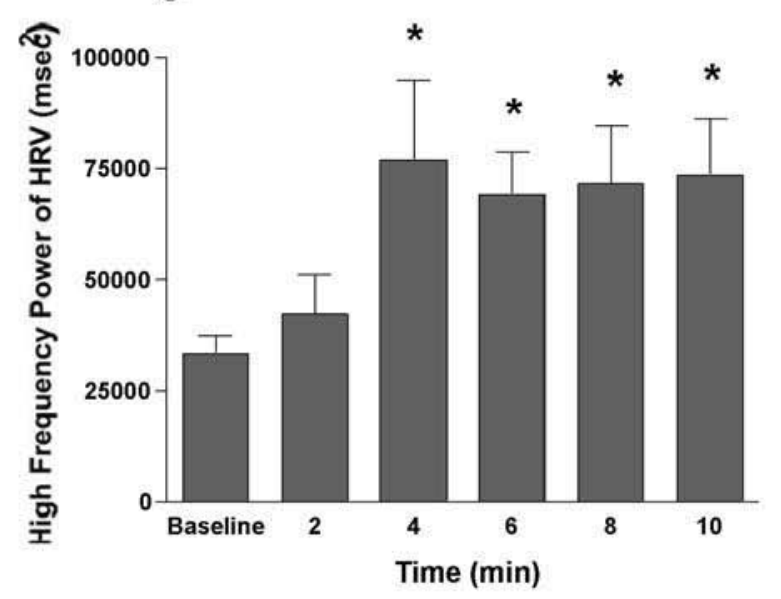

B

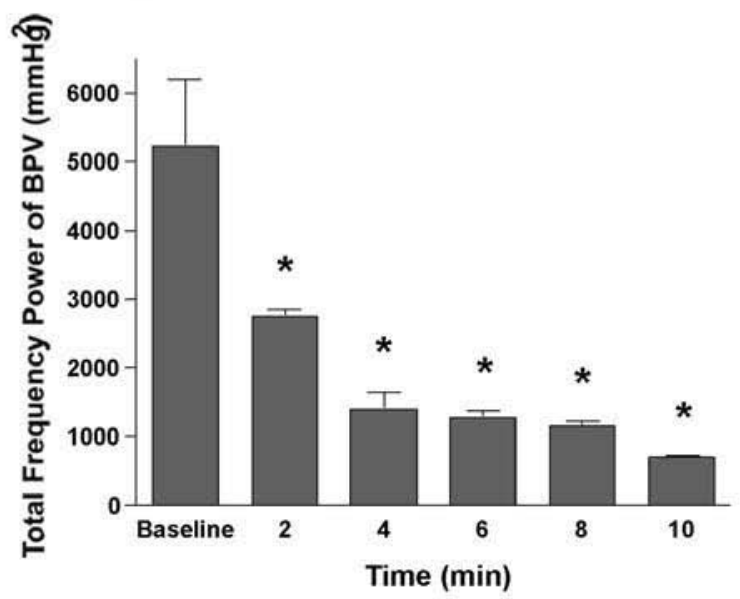

D

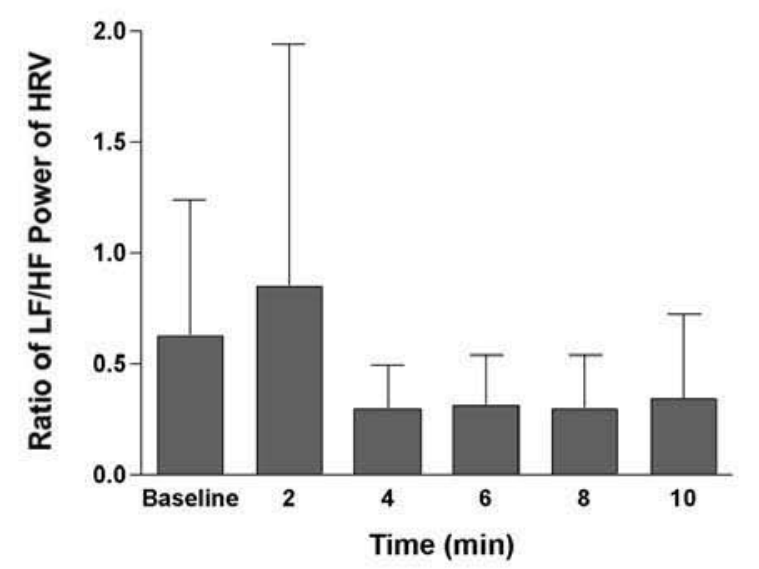

FIGURE Somatosensory block levels (A), total frequency power of blood pressure variability (BPV, sum of levels 2, 4, 8, 16 and 32) (B), high frequency power of heart rate variability (HRV, sum of levels 2, 4, and 8) (C), and the ratio of low to high frequency power of HRV (D) over time post-epidural for labour. Values are mean $\pm \mathrm{SD},{ }^{*} P<0.01$ vs baseline.

ity in our patients. Hanss et al. ${ }^{15,16,18}$ have used the ratio of LF:HF power of HR variability to predict and prevent hypotension with spinal anesthesia. These studies are very different in their design than the one presented here. They used preoperative values of the LF:HF ratio to predict the risk of intraoperative hypotension. They did not follow the changes in the ratio as spinal anesthesia progressed. The results from the present study are similar to the ones we presented previously ${ }^{2}$ in that there was no correlation between the change in the LF:HF ratio and the changes in BP variability with the onset of epidural analgesia. This is not necessarily surprising since there is considerable controversy as to the usefulness of the LF:HF ratio as a monitor of sympathetic tone. ${ }^{25-29}$

One of the main limitations of HR and BP variability analysis is that the process does not track in real time. Signal processing is necessary and post hoc analysis of the data limits the use of these parameters as a useful predictor of events in the operating room. However, as this analysis gains popularity and its potential applications continue to evolve, it is most 
likely only a question of time before real time online analysis is available for use in the operating room. Bispectral index is a good example of a similar technology that was developed for real time analysis in the operating room with good prognostic potential. ${ }^{30}$ Other limiting factors include the possibility that the results may not be generalizable to non-labouring patients receiving epidural analgesia as part of a multimodal analgesia strategy in the perioperative setting, and whether the present results can be extrapolated to spinal anesthesia in the operating room. More studies are needed to answer these limitations.

In conclusion, both HR and BP variability show significant changes with epidural analgesia for labour, but only BP variability correlates with progression of the somatosensory block. Analysis of BP variability could therefore be a useful tool to monitor both the decrease in sympathetic activity and the progression of somatosensory block following onset of epidural analgesia in labouring parturients.

\section{References}

1 Miller RD. Miller's Anesthesia, $6^{\text {th }}$ ed. Philadelphia: Elsevier Churchil Levingstone; 2005.

2 Deschamps A, Kaufman I, Backman SB, Plourde G. Autonomic nervous system response to epidural analgesia in laboring patients by wavelet transform of heart rate and blood pressure variability. Anesthesiology 2004; 101: 21-7.

3 Pichot V, Gaspoz JM, Molliex S, et al. Wavelet transform to quantify heart rate variability and to assess its instantaneous changes. J Appl Physiol 1999; 86: 1081-91.

4 de Boer RW, Karemaker JM, Strackee J. On the spectral analysis of blood pressure variability. Am J Physiol 1986; 251(3 Pt 2): H685-7.

5 Pichot V, Buffiere S, Gaspoz JM, et al. Wavelet transform of heart rate variability to assess autonomic nervous system activity does not predict arousal from general anesthesia. Can J Anesth 2001; 48: 859-63.

6 Anonymous. Heart rate variability: standards of measurement, physiological interpretation and clinical use. Task Force of the European Society of Cardiology and the North American Society of Pacing and Electrophysiology. Circulation 1996; 93: 1043-65.

7 Arakawa M, Goto F. Power spectral analysis of heart rate and blood pressure variability in lumbar epidural anaesthesia. Can J Anaesth 1994; 41: 680-7.

8 Evans JM, Ziegler MG, Patwardhan AR, et al. Gender differences in autonomic cardiovascular regulation: spectral, hormonal, and hemodynamic indexes. J Appl Physiol 2001; 91: 2611-8.

9 Bauernschmitt R, Malberg H, Wessel N, Kopp B, Schirmbeck EU, Lange R. Impairment of cardiovascular autonomic control in patients early after cardiac surgery. Eur J Cardiothorac Surg 2004; 25: 320-6.

10 Hughson RL, Maillet A, Dureau G, Yamamoto $\Upsilon$, Gharib C. Spectral analysis of blood pressure variability in heart transplant patients. Hypertension 1995; 25(4 Pt 1): 643-50.

11 Backman SB, Stein RD, Polosa C. Organization of the sympathetic innervation of the forelimb resistance vessels in the cat. Anesth Analg 1999; 88: 320-5.

12 Deschamps A, Backman SB, Novak V, Plourde G, Fiset $P$, Chartrand D. Effects of the anticholinesterase edrophonium on spectral analysis of heart rate and blood pressure variability in humans. J Pharmacol Exp Ther 2002; 300: 112-7.

13 Pagani $M$. Circadian heart rate and blood pressure variability considered for research and patient care. Int J Cardiol 2003; 87: 29-30.

14 Pichot V, Roche F, Gaspoz JM, et al. Relation between heart rate variability and training load in middle-distance runners. Med Sci Sports Exerc 2000; 32: 1729 36.

15 Hanss $R$, Bein B, Ledowski T, et al. Heart rate variability predicts severe hypotension after spinal anesthesia for elective cesarean delivery. Anesthesiology 2005; 102: 1086-93.

16 Hanss $R$, Bein B, Weseloh $H$, et al. Heart rate variability predicts severe hypotension after spinal anesthesia. Anesthesiology 2006; 104: 537-45.

17 Chamchad D, Arkoosh VA, Horrow JC, et al. Using heart rate variability to stratify risk of obstetric patients undergoing spinal anesthesia. Anesth Analg 2004; 99: 1818-21.

18 Hanss R, Bein B, Francksen H, et al. Heart rate variability-guided prophylactic treatment of severe hypotension after subarachnoid block for elective cesarean delivery. Anesthesiology 2006; 104: 635-43.

19 Maier P, Toepfer M, Dambacher M, Theisen K, Roskamm H, Frey $A W$. Heart rate variability and its relation to ventricular tachycardia in patients with coronary artery disease. Clin Sci (Lond) 1996; 91Suppl: 67.

20 Lombardi F. Chaos theory, heart rate variability, and arrhythmic mortality. Circulation 2000; 101: 8-10.

21 Winchell RJ, Hoyt DB. Analysis of heart-rate variability: a noninvasive predictor of death and poor outcome in patients with severe head injury. J Trauma 1997; 43: 927-33.

22 Schmidt H, Muller-Werdan U, Hoffmann T, et al. Autonomic dysfunction predicts mortality in patients with multiple organ dysfunction syndrome of different age groups. Crit Care Med 2005; 33: 1994-2002.

23 Winchell RJ, Hoyt DB. Spectral analysis of heart rate variability in the ICU: a measure of autonomic func- 
tion. J Surg Res 1996; 63: 11-6.

24 Schmidt HB, Werdan K, Muller-Werdan U. Autonomic dysfunction in the ICU patient. Curr Opin Crit Care 2001; 7: 314-22.

25 Hopf HB, Skyschally A, Heusch G, Peters J. Low-frequency spectral power of heart rate variability is not a specific marker of cardiac sympathetic modulation. Anesthesiology 1995; 82: 609-19.

26 Notarius CF, Floras JS. Limitations of the use of spectral analysis of heart rate variability for the estimation of cardiac sympathetic activity in heart failure.

Europace 2001; 3: 29-38.

27 Landry DP, Bennett FM, Oriol NE. Analysis of heart rate dynamics as a measure of autonomic tone in obstetrical patients undergoing epidural or spinal anesthesia. Reg Anesth 1994; 19: 189-95.

28 Skyschally A, Breuer HW, Heusch G. The analysis of heart rate variability does not provide a reliable measurement of cardiac sympathetic activity. Clin Sci (Lond) 1996; 91 Suppl: 102-4.
29 Pagani M, Lucini D, Rimoldi O, et al. Low and high frequency components of blood pressure variability. Ann N Y Acad Sci 1996; 783: 10-23.

30 Monk TG. Processed EEG and patient outcome. Best Pract Res Clin Anaesthesiol 2006; 20: 221-8.

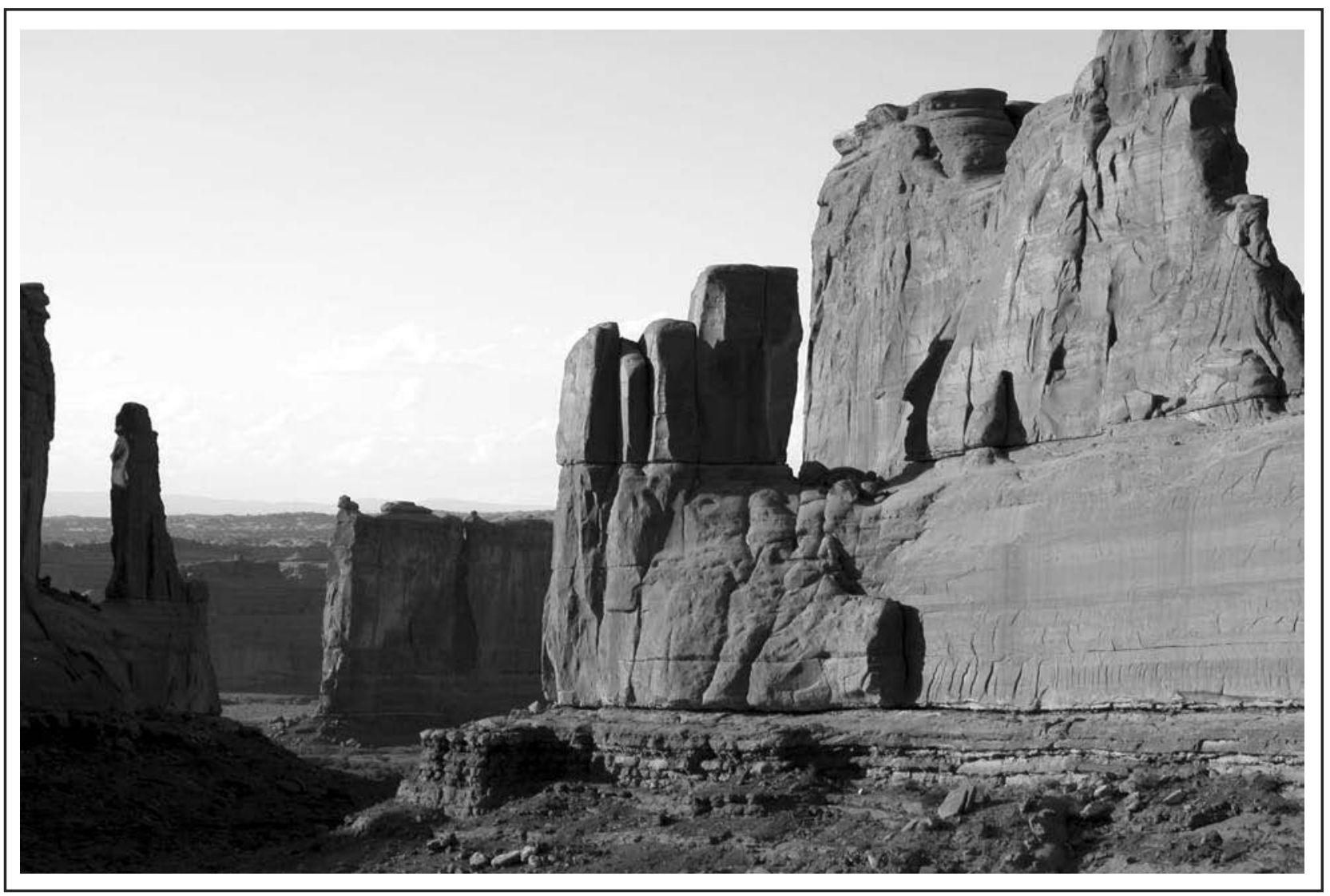

Arches National Park - USA 